\title{
INHALT / TABLE OF CONTENTS
}

\section{Teil $1 /$ Part 1}

Einleitung zur zweiten Auflage $\ldots \ldots \ldots \ldots \ldots \ldots \ldots \ldots$ vii

Introduction to the Second Edition $\ldots \ldots \ldots \ldots \ldots \ldots \ldots \ldots \ldots$

Danksagung / Acknowledgements . . . . . . . . . . . . . . xli

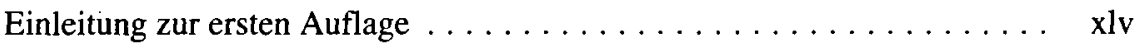

Introduction to the First Edition $\ldots \ldots \ldots \ldots \ldots \ldots$ li

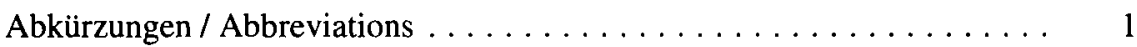

Kommentierte Bibliographie 1955-1980 / Annotated Bibliography 1955-1980

I. Bibliographien und Ähnliches / Bibliographies and Similar

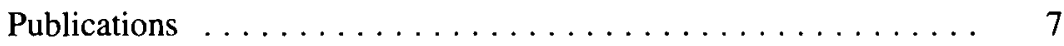

II. Sammelbände / Collections of Articles ............... 21

III. Dissertationen / Dissertations and Theses . . . . . . . . . . . . 31

IV. Artikel und kleinere Beiträge / Articles and Other Contributions ... 63

V. Buicher / Books ........................ 515

\section{Teil 2 / Part 2}

Kommentierte Bibliographie 1980-1997 mit Nachträgen zu Teil 1: 19551980 / Annotated Bibliography 1980-1997 with Addenda to Part 1: 1955-1980

I. Bibliographien, Forschungsberichte und Ähnliches / Bibliographies, Research Reports and Similar Publications . . . . . . . . . . . . . 627

II. Sammelbände, Zeitschriften, Mitteilungsblätter, Sondernummern, Franz-Kafka-Gesellschaften / Collections of Articles, Periodicals, Newsletters, Special Issues, Franz Kafka Societies . . . . . . . . . . 637

III. Dissertationen und Ähnliches / Dissertations and Theses . . . . . . . . . 649

IV. Artikel und kleinere Beiträge / Articles and Other Contributions . . . 663

V. Bücher / Books .......................... 885

Addenda . . . . . . . . . . . . . . . . . . . . . . . . . 961

Englische Übersetzungen der Buchkommentare / English Translations of

Book Commentaries . . . . . . . . . . . . . . . . . . . 999

Sach- und Namenregister / Subject Index and Index of Names $\ldots \ldots \ldots 1081$

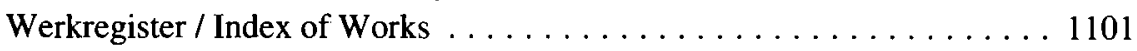


